\title{
Vaspin prevents leptin-induced inflammation and catabolism by inhibiting the activation of nuclear factor- $\kappa B$ in rat chondrocytes
}

\author{
JIA-PENG BAO, LANG-HAI XU, JI-SHENG RAN, YAN XIONG and LI-DONG WU \\ Department of Orthopedic Surgery, The Second Affiliated Hospital, School of Medicine, \\ Zhejiang University, Hangzhou, Zhejiang 310009, P.R. China
}

Received July 3, 2016; Accepted May 4, 2017

DOI: $10.3892 / \mathrm{mmr} .2017 .6911$

\begin{abstract}
The present study aimed to investigate the function and possible underlying mechanism of various concentrations of visceral adipose tissue-derived serine protease inhibitor (vaspin) on leptin-induced inflammatory and metabolic responses in rat chondrocytes. Rat articular chondrocytes were isolated and treated with different concentrations of vaspin, which was followed by stimulation with leptin. The expression of genes, secretion of nitric oxide and tumor necrosis factor- $\alpha$, and activation of the nuclear factor (NF)- $\kappa B$ pathway were analyzed by reverse transcription-quantitative polymerase chain reaction, ELISA and western blotting. The results demonstrated that vaspin inhibited the leptin-induced upregulated gene expression levels of leptin receptor (OB-Rb), a disintegrin and metalloprotease with thrombospondin motifs (ADAMTS)-4, ADAMTS-5, matrix metalloproteinase (MMP)-2 and MMP-9, and the secretion of NO and TNF- $\alpha$, in a dose-dependent manner. The phosphorylation of inhibitor

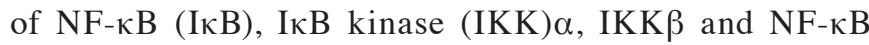
were also promoted by leptin in the chondrocytes, which were also suppressed by increased concentration of vaspin. Taken together, results demonstrated that vaspin prevented leptin-induced inflammation and catabolism by inhibiting the activation of NF- $\mathrm{kB}$ in rat chondrocytes.
\end{abstract}

\section{Introduction}

Osteoarthritis $(\mathrm{OA})$ is a degenerative disease. It is characterized by articular cartilage loss, osteophyte formation, synovium alterations and functional changes of entire joints (1). Injury, impaired muscle function, sex and obesity are modifiable risk factors in the pathophysiology of OA (2). Obesity, which

Correspondence to: Professor Li-Dong Wu, Department of Orthopedic Surgery, The Second Affiliated Hospital, School of Medicine, Zhejiang University, 88 Jiefang Road, Hangzhou, Zhejiang 310009, P.R. China

E-mail:1dwu@yahoo.com

Key words: osteoarthritis, visceral adipose tissue-derived serine protease inhibitor, leptin, inflammation, nuclear factor- $\kappa \mathrm{B}$ is considered to be one of the major risk factors for OA, may induce cartilage damage by enhancing the mechanical pressure on the weight-bearing joints, including the hip and knee (3). However, the association between obesity and OA in non-weight bearing joints, including the wrists and fingers, has also been reported (4), and a previous study suggested that additional cytokines produced by white adipose tissue (WAT), termed adipokines, may also be involved during the progression of OA (5). In addition, it has been demonstrated that metabolic surplus and nutrient overload can increase metabolic inflammation. Adipokines, may be involved in the progression of OA by increasing the expression of degradative enzymes and pro-inflammatory cytokines, leading to synovial hyperplasia and cartilage extracellular matrix degradation (6). Of these adipokines, leptin is considered to be the most important. The synovial fluid concentration of leptin has been identified to be significantly associated with the progression of OA (7) and joint pain (8). Leptin has also been shown to induce the expression of metabolic and inflammatory factors, including a disintegrin and metalloprotease with thrombospondin motifs (ADAMTs), matrix metalloproteinases (MMPs), nitric oxide (NO), prostaglandin E2, cyclooxygenase-2 (COX-2) and interleukin-1 $\beta$

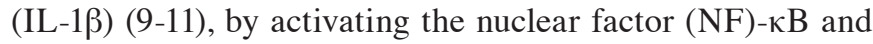
mitogen-activated protein kinase signaling pathways $(12,13)$.

Visceral adipose tissue-derived serine protease inhibitor (vaspin) is a novel cytokine, which was first identified in the visceral adipose tissue of Zucker fatty rats in 2005 (14). Vaspin has been identified in several human tissues, including serum, omental adipose tissue and placenta (15-17), and increased serum levels of vaspin in diabetes and obesity in humans have been reported (18). Vaspin exerts an insulin-sensitizing effect, which improves insulin sensitivity and inhibits the gene expression levels of tumor necrosis factor (TNF)- $\alpha$ and leptin, which are associated with insulin resistance (14). Vaspin is considered to be a novel adipokine with anti-inflammatory properties, and links between vaspin and arthritis have been demonstrated $(19,20)$. Senolt et al (19) identified that the synovial fluid levels of vaspin were higher in patients with rheumatoid arthritis (RA), compared with those with OA. Furthermore, investigations by Maijer et al (20) identified that serum levels of vaspin may assist in predicting the progression of RA in autoantibody-positive individuals. These findings suggest a possible role of vaspin during the development of arthritis, on which further investigations are required. 
In our previous studies, it was identified that the joint tissues in OA, including synovium, cartilage and osteophytes, exhibited protein expression of vaspin (21). It was also demonstrated that vaspin suppressed the IL-1 $\beta$-induced production of inflammatory and catabolic factors in chondrocytes (22). Vaspin and leptin are important during the pathophysiology of OA; however, the interaction between vaspin and leptin in chondrocytes remains to be fully elucidated. The present study examined the effect of vaspin on the leptin-induced gene expression of leptin receptor (OB-Rb), ADAMTS-4, ADAMTS-5, MMP-2 and MMP-9, and the effect of vaspin on leptin-induced production of NO and TNF- $\alpha$ in rat chondrocytes. In addition, the present study investigated whether the $\mathrm{NF}-\kappa \mathrm{B}$ signaling pathway was involved in the process.

\section{Materials and methods}

Cell culture and treatment. The present study was approved by the Ethics Committee of the Second Affiliated Hospital, School of Medicine, Zhejiang University, Hangzhou, China. Normal articular cartilage was isolated from the knee and femoral head of four-week-old Sprague-Dawley rats (160-180 g), which were obtained from the Animal Center of Zhejiang University (Hangzhou, China). A total of 6 rats were used in the present study, and rats were anesthetized with sodium pentobarbital (Sigma-Aldrich; Merck KGaA, Darmstadt, Germany; 40 mg/kg body weight; intraperitoneal injection) and sacrificed by cervical dislocation after anesthetization for cartilage harvest. The harvested cartilage samples were then cut into $1 \mathrm{~mm}^{3}$ cubes, followed by digestion with $0.2 \%$ pronase (Sigma-Aldrich; Merck $\mathrm{KGaA}$ ) at $37^{\circ} \mathrm{C}$ for $30 \mathrm{~min}$, and subsequent digestion with $0.1 \%$ collagenase at $37^{\circ} \mathrm{C}$ for $4 \mathrm{~h}$. The cells from one rat were centrifuged at $1,000 \mathrm{x}$ g for $5 \mathrm{~min}$, then resuspended and plated in a $25 \mathrm{~cm}^{2}$ culture flask (Corning Incorporated, Corning, NY, USA) in Dulbecco's modified Eagle's medium (Gibco; Thermo Fisher Scientific, Inc., Waltham, MA, USA) containing $10 \%$ fetal bovine serum (Gibco; Thermo Fisher Scientific, Inc.) and antibiotics (100 U/ml penicillin; Invitrogen; Thermo Fisher Scientific, Inc.) and $100 \mu \mathrm{g} / \mathrm{ml}$ streptomycin (Invitrogen; Thermo Fisher Scientific, Inc.). The chondrocytes were cultured in a $5 \% \mathrm{CO}_{2}$ atmosphere at $37^{\circ} \mathrm{C}$, designated passage $0(\mathrm{P} 0)$. The confluent primary chondrocytes were passaged at a ratio of $1: 3$, designated $\mathrm{P} 1, \mathrm{P} 2$ and $\mathrm{P} 3$. The $\mathrm{P} 3$ chondrocytes were used in the subsequent experiments.

The rat chondrocytes were plated at a density of $1 \times 10^{5}$ cells/well in a 6-well plate (serum-free) overnight. The cells were then pre-treated with different concentrations of vaspin $(0,10,50,100$ and $300 \mathrm{ng} / \mathrm{ml})$ for $1 \mathrm{~h}$ prior to treatment with leptin $(100 \mathrm{ng} / \mathrm{ml})$ for $24 \mathrm{~h}$ at $37^{\circ} \mathrm{C}$. The culture medium was collected for NO and TNF- $\alpha$ measurement, and the cells were harvested for reverse transcription-quantitative polymerase chain reaction (RT-qPCR) and western blot analyses.

For the analysis of $\mathrm{NF}-\kappa \mathrm{B}, 5 \times 10^{6}$ rat chondrocytes were plated in serum-free medium for $24 \mathrm{~h}$, treated with various concentrations of vaspin $(0,10,50,100$ and $300 \mathrm{ng} / \mathrm{ml})$ for $1 \mathrm{~h}$ prior to treatment with leptin $(100 \mathrm{ng} / \mathrm{ml})$ for $24 \mathrm{~h}$. The cells were collected for analysis of the $\mathrm{NF}-\kappa \mathrm{B}$ signaling pathway.

RT-qPCR analysis of the expression levels of $O B-R b$, ADAMTS-4, ADAMTS-5, MMP-2 and MMP-9. Total
Table I. Primers of target genes for reverse transcription-quantitative polymerase chain reaction analysis.

\begin{tabular}{ll}
\hline Target gene & \multicolumn{1}{c}{ Sequence $\left(5^{\prime}-3^{\prime}\right)$} \\
\hline MMP-2 & F: AGGATGGAGGCACGATTGG \\
& R: CTTGATGATGGGCGACGGT \\
FMP-9 & F: ACCCCATGTATCACTACCACGAG \\
& R: TCAGGTTTAGAGCCACGACCAT \\
ADAMTS-4 & F: GCCAGCAACCGAGGTCCCATA \\
& R: CCACCAGTGTCTCCACGAATCTAC \\
ADAMTS-5 & F: GGGGTCAGTGTTCTCGCTCTTG \\
& R: GCCGTTAGGTGGGCAGGGTAT \\
18S & F: TTGACGGAAGGGCACCA \\
& R: CAGACAAATCGCTCCACCAA
\end{tabular}

F, forward; R, reverse; MMP, matrix metalloproteinase; ADAMTS, a disintegrin and metalloprotease with thrombospondin motifs.

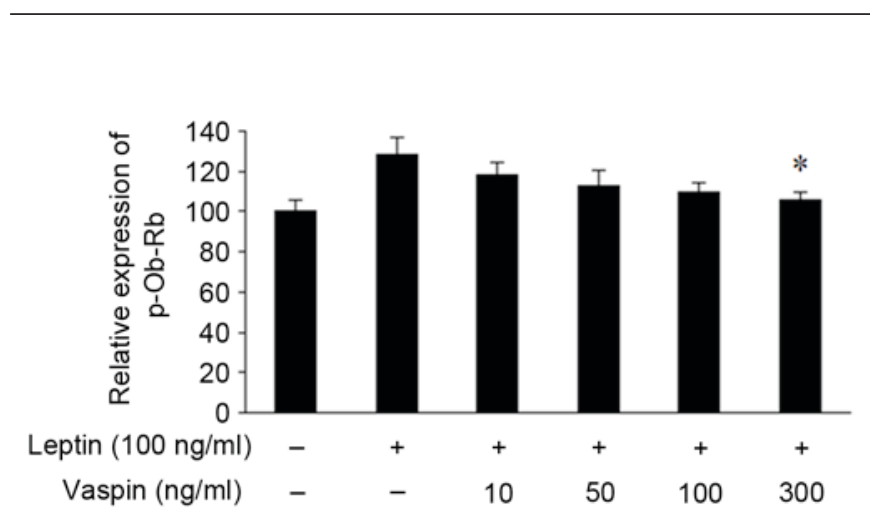

Figure 1. Effects of vaspin on leptin-induced mRNA expression of $\mathrm{OB}-\mathrm{Rb}$ in rat chondrocytes. Cells were pre-treated with various concentrations of vaspin $(0,10,50,100$ and $300 \mathrm{ng} / \mathrm{ml})$ for $1 \mathrm{~h}$ prior to treatment with leptin $(100 \mathrm{ng} / \mathrm{ml})$ for $24 \mathrm{~h} .{ }^{*} \mathrm{P}<0.05$, compared with cells stimulated with leptin alone. OB-Rb, leptin receptor; $\mathrm{p}$-, phosphorylated.

RNA was isolated from the samples using TRIzol reagent (Invitrogen; Thermo Fisher Scientific, Inc.) according to the manufacturer's protocol. A total of $1 \mu \mathrm{g}$ RNA was used for the synthesis of first strand cDNA, using the PrimeScript-RT reagent kit (Takara Bio, Inc., Otsu, Japan). The qPCR procedure was then performed using SYBR Premix Ex Taq (Takara Bio, Inc.). The primers used for the target genes were as follows: ADAMTS4, forward 5'-GCCAGCAACCGAGGT CCCATA-3' and reverse 5'-CCACCAGTGTCTCCACGAATC TAC; ADAMTS5, forward 5'-GGGGTCAGTGTTCTCGCT CTTG-3' and reverse GCCGTTAGGTGGGCAGGGTAT-3'; MMP-2, forward 5'-AGGATGGAGGCACGATTGG-3' and reverse 5'-CTTGATGATGGGCGACGGT-3'; MMP-9, forward 5'-ACCCCATGTATCACTACCACGAG-3' and reverse 5'-TCA GGTTTAGAGCCACGACCAT-3'; 18S, forward 5'-TTGACG GAAGGGCACCA-3' and reverse 5'-CAGACAAATCGCTCC ACCAA-3' (NR046237.1) (Table I). Parallel amplification of $18 \mathrm{~S}$ was performed as an internal control. The RT-qPCR program was $95^{\circ} \mathrm{C}$ for $1 \mathrm{~min}$, then 45 cycles of $95^{\circ} \mathrm{C}$ for $10 \mathrm{sec}$ and $63^{\circ} \mathrm{C}$ for $25 \mathrm{sec}$. The melt curve analysis of amplification products was done at the end of each PCR reaction to confirm that only one PCR product was amplified and detected. The relative PCR data were analyzed using the $2^{-\Delta \Delta C \mathrm{q}}$ method (23). 

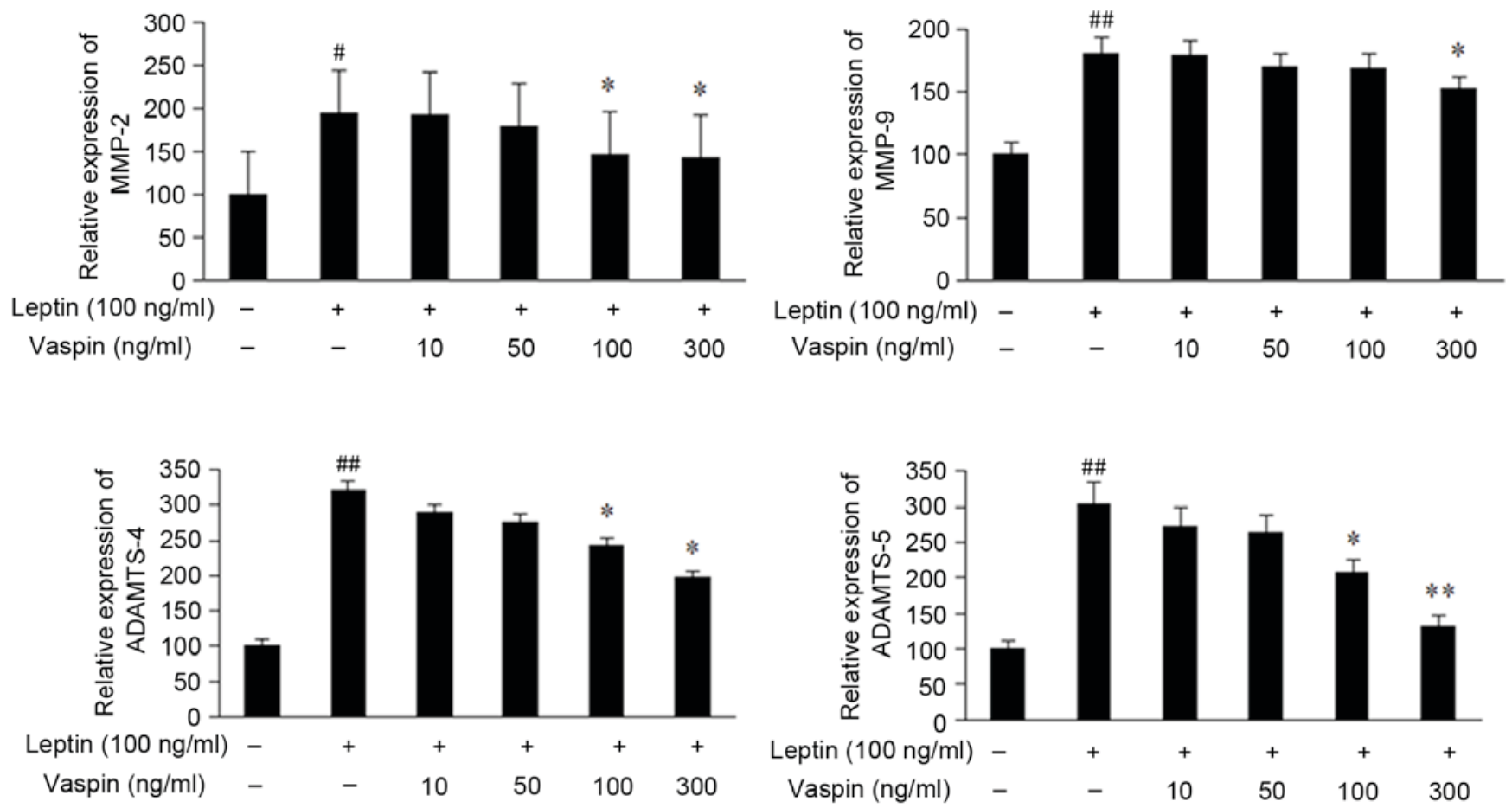

Figure 2. Effects of vaspin on leptin-induced mRNA expression of ADAMTS-4, ADAMTS-5, MMP-2 and MMP-9 in rat chondrocytes. Cells were pre-treated with various concentrations of vaspin $(0,10,50,100$ and $300 \mathrm{ng} / \mathrm{ml})$ for $1 \mathrm{~h}$ prior to treatment with leptin $(100 \mathrm{ng} / \mathrm{ml})$ for $24 \mathrm{~h}$. ${ }^{*} \mathrm{P}<0.05$ and ${ }^{* *} \mathrm{P}<0.01$, compared with cells stimulated with leptin alone. ${ }^{\#} \mathrm{P}<0.05$ and ${ }^{\# \#} \mathrm{P}<0.01$, compared with control group. ADAMTS, a disintegrin and metalloprotease with thrombospondin motifs; MMP, matrix metalloproteinase.

ELISA analysis of the levels of NO and TNF- $\alpha$ in culture medium. The rat chondrocytes were pre-treated with different concentrations of vaspin $(0,10,50,100$ and $300 \mathrm{ng} / \mathrm{ml})$ for $1 \mathrm{~h}$ prior to treatment with leptin $(100 \mathrm{ng} / \mathrm{ml})$ for $24 \mathrm{~h}$. The culture medium was collected and then analyzed using commercially available ELISA kits according to the manufacturer's protocols (R\&D Systems, Inc., Minneapolis, MN, USA).

Western blot analysis. All cells were washed twice with ice-cold phosphate-buffered saline (PBS) and harvested, following which the cytoplasmic proteins were isolated using an extraction kit (Beyotime Institute of Biotechnology, Jiangsu, China). The proteins were resolved using $10 \%$ sodium dodecyl sulfate polyacrylamide gel electrophoresis (60 $\mu \mathrm{g}$ in each lane), transferred onto nitrocellulose membranes and then probed with 1:1,000 dilution of primary antibodies against phosphorylated

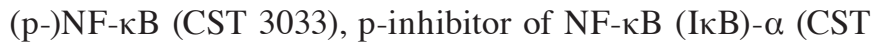
2859), p-IкB kinase (IKK)- $\alpha$ and p-IKK- $\beta$ (CST 2078; all from Cell Signaling Technology, Inc., Dallas, TX, USA) overnight at $4^{\circ} \mathrm{C}$. The membranes were then washed and incubated for $1 \mathrm{~h}$ at room temperature with 1:10,000 of goat anti-rabbit/mouse secondary antibody (31460 and 32230; Invitrogen; Thermo Fisher Scientific, Inc.), followed by visualization with enhanced chemiluminescence using a commercially available kit (Cell Signaling Technology, Inc.). The density of bands was measured by densitometry using Quantity One version 4.6.2 software (Bio-Rad Laboratories Inc., Hercules, CA, USA).

Statistical analysis. All data are expressed as the mean \pm standard deviation. Statistical analyses were performed using SPSS 19.0 software (IBM SPSS, Armonk, NY, USA) for
Windows. Statistical significance was assessed using Student's $\mathrm{t}$-test and one-way analysis of variance. $\mathrm{P}<0.05$ was considered to indicate a statistically significant difference.

\section{Results}

Effects of vaspin on leptin-induced $m R N A$ expression of $O B-R b$ in rat chondrocytes. Stimulation with leptin for $24 \mathrm{~h}$ resulted in upregulated mRNA expression of $\mathrm{p}-\mathrm{OB}-\mathrm{Rb}$ in chondrocytes. Vaspin at various concentrations inhibited the gene expression of p-OB-Rb in a dose-dependent manner (Fig. 1).

Effects of vaspin on leptin-induced mRNA levels of ADAMTS-4, ADAMTS-5, MMP-2 and MMP-9 in rat chondrocytes. As demonstrated in Fig. 2, the chondrocytes not exposed to leptin exhibited low gene expression levels of ADAMTS-4, ADAMTS-5, MMP-2 and MMP-9. Leptin significantly induced the expression of these genes, whereas this induction was inhibited by vaspin.

Effects of vaspin on leptin-induced secretion of NO and TNF- $\alpha$ in rat chondrocytes. The secretion of NO and TNF- $\alpha$ were increased in chondrocytes treated with leptin for $24 \mathrm{~h}$, which was significantly inhibited by vaspin in a dose-dependent manner (Fig. 3).

Effects of vaspin on expression of the $N F-\kappa B$ signaling pathway stimulated by leptin in rat chondrocytes. As demonstrated in Fig. 4A and B, the results of the western blot analysis demonstrated that the phosphorylation levels of NF- $\kappa \mathrm{B}, \mathrm{I} \kappa \mathrm{B} \alpha$, IKK $\alpha$ and IKK $\beta$ were markedly increased 


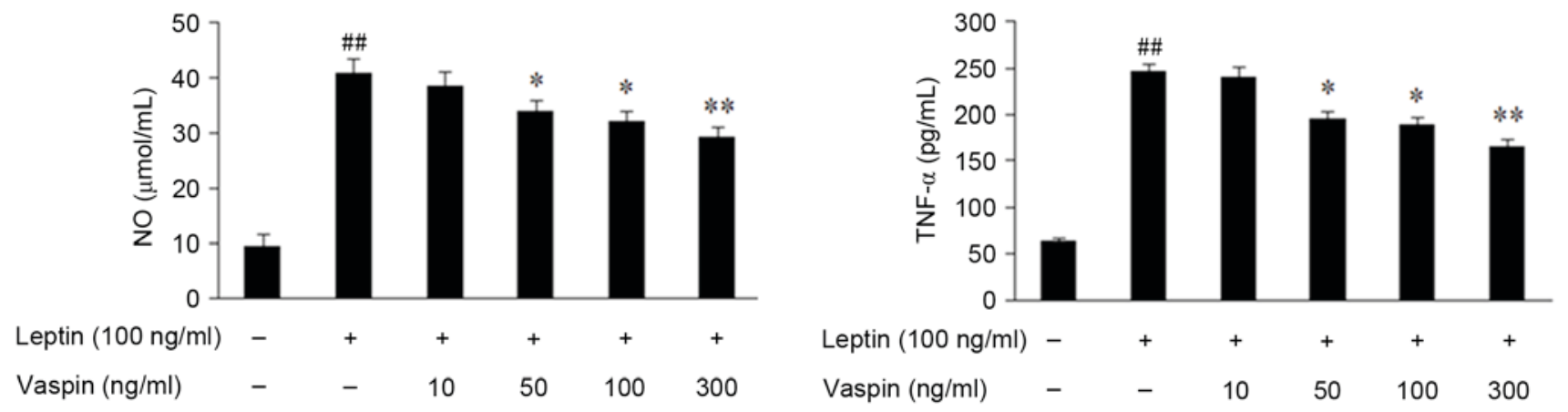

Figure 3. Effects of vaspin on leptin-induced production of NO and TNF- $\alpha$ in rat chondrocytes. Cells were pretreated with various concentrations of vaspin $(0$, $10,50,100$ and $300 \mathrm{ng} / \mathrm{ml})$ for $1 \mathrm{~h}$ prior to treatment with leptin $(100 \mathrm{ng} / \mathrm{ml})$ for $24 \mathrm{~h}$. $\mathrm{*}<0.05$ and ${ }^{* *} \mathrm{P}<0.01$, compared with cells stimulated with leptin alone. ${ }^{\# \#} \mathrm{P}<0.01$, compared with control group. NO, nitric oxide; TNF- $\alpha$, tumor necrosis factor- $\alpha$.

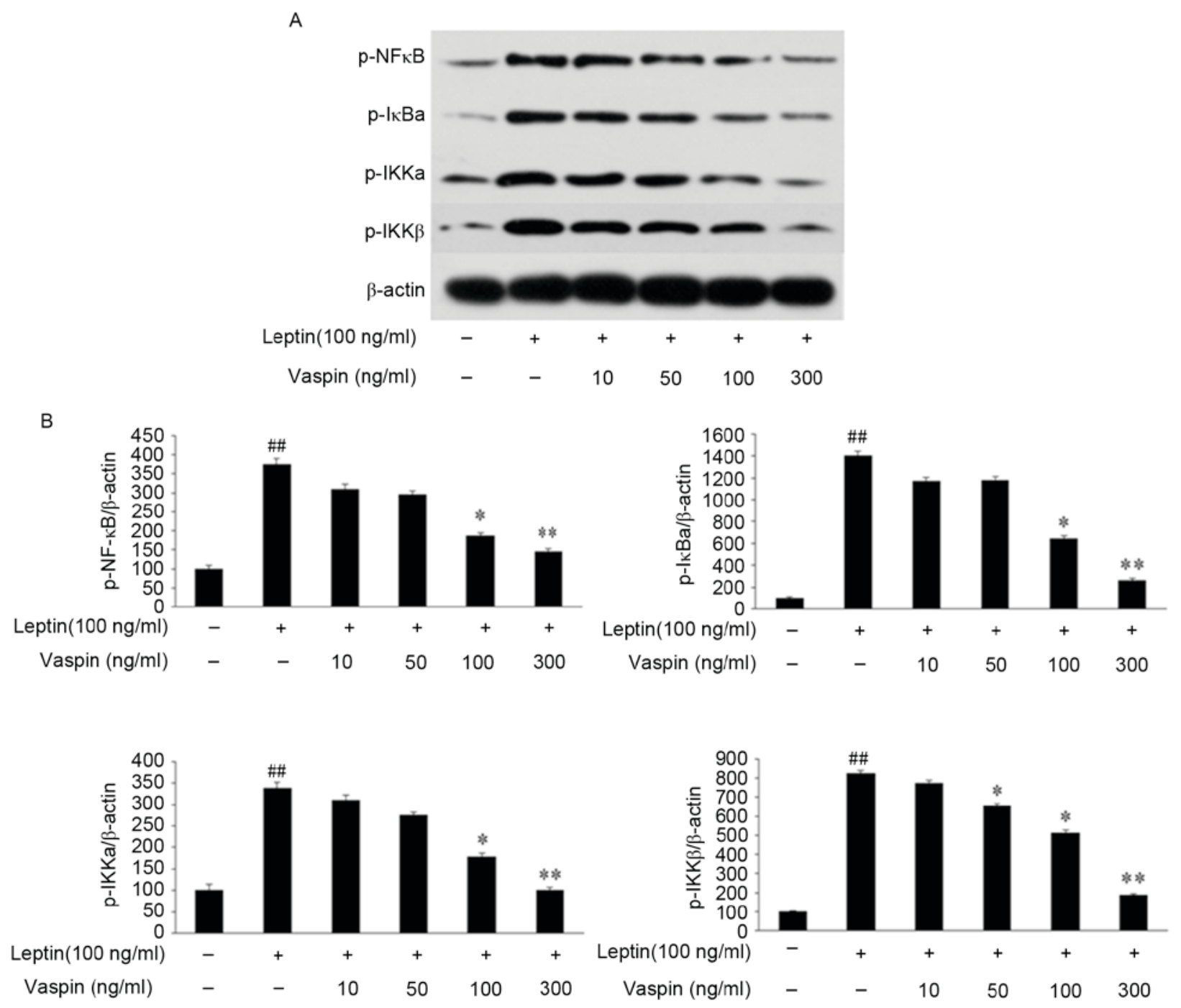

Figure 4. Vaspin inhibits the NF- $\mathrm{kB}$ signaling pathway induced by leptin in rat chondrocytes. (A) Cells were pretreated with various concentrations of vaspin $(0,10,50,100$ and $300 \mathrm{ng} / \mathrm{ml})$ for $1 \mathrm{~h}$ prior to treatment with leptin $(100 \mathrm{ng} / \mathrm{ml})$ for $24 \mathrm{~h}$. (B) " $\mathrm{P}<0.05$ and ${ }^{* *} \mathrm{P}<0.01$, compared with cells stimulated with leptin

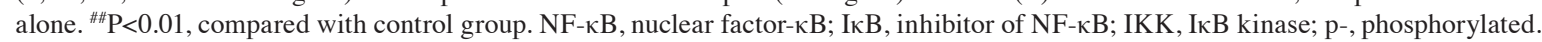

following stimulation with leptin. Vaspin pretreatment inhibited the leptin-induced phosphorylation of NF- $\mathrm{B}$, $\mathrm{I} \kappa \mathrm{B} \alpha, \mathrm{IKK} \alpha$ and IKK $\beta$ in a dose-dependent manner, and this was significant at concentrations of $100 \mathrm{ng} / \mathrm{ml}(\mathrm{P}<0.05)$ and $300 \mathrm{ng} / \mathrm{ml}(\mathrm{P}<0.01)$.

\section{Discussion}

Adipokines are cytokines secreted by WAT and include adiponectin, leptin, resistin, vaspin and apelin. These adipokines have been demonstrated to be involved in insulin sensitivity, 
lipid metabolism, angiogenesis, immunity and inflammation $(24,25)$. Adipokines can damage cartilage homeostasis by regulating local inflammatory processes or inducing the structural degradation of joints (6). Leptin, the first adipokine to be identified (26), is considered to have pro-inflammatory effects, and has been demonstrated to correlate with clinical and biological measurements of RA activity (27). Wang et al (6) identified that leptin was positively correlated with body mass index, fat mass and body weight among individuals with OA. Furthermore, our previous study suggested that the overexpression of leptin and its receptor induced the production of MMPs and IL-1 $\beta$ (28). These results confirmed that leptin has a catabolic and pro-inflammatory role during the pathological process of OA.

Vaspin, which has been identified to improve glucose tolerance and insulin sensitivity in the pathogenesis of metabolic syndrome (29), also possesses anti-inflammatory effects (30-32). Evidence has demonstrated that vaspin can attenuate the cytokine-induced gene expression of adhesion molecules in vascular smooth muscle cells (30) and vascular endothelial cells (31). In addition, vaspin has been shown to inhibit the expression of $\mathrm{TNF}-\alpha$, resistin and leptin in chronic hepatitis (32). The results of our previous study demonstrated that vaspin also reduces the IL-1 $\beta$-induced inflammatory and catabolic responses (22). As vaspin can improve insulin sensitivity, reverse the expression of leptin (14) and suppress the expression of leptin in chronic hepatitis (32), the present study hypothesized that vaspin may have interactions with leptin, and suppress the inflammatory factors induced by leptin in chondrocytes.

OB-R can recruit cytoplasmic kinases, including Janus kinase 2 to initiate leptin signaling upon leptin binding (33). OB-R contains six alternatively spliced isoforms, which have the same extracellular binding domains, but different length cytoplasmic domains, including one long isoform (OB-Rb), four short isoforms (OB-Ra, OB-Rc, OB-Rd and OB-Rf), and one soluble isoform (OB-Re). However, OB-Rb is the only isoform containing the full intracellular domain able to transduce leptin-binding signals to the nucleus (34). The present study suggested that vaspin suppressed the leptin signaling pathways via inhibiting the expression of OB-Rb induced by leptin, which attenuated the catabolic effect of leptin on rat chondrocytes. Further investigations are required to elucidate the exact mechanism underlying the regulation of OB-Rb by vaspin.

The present study identified that leptin significantly induced the gene expression of ADAMTS-4, ADAMTS-5, MMP-2 and MMP-9, which was consistent with our previous results (28). ADAMTS-4 and ADAMTS-5 are two important aggrecanases, which lead to structural damage during the progression of joint OA (35). By contrast, high levels of MMP-2 and MMP-9 were identified in OA, suggesting they may contribute to cartilage destruction when activated (36). The results also demonstrated that vaspin significantly inhibited the leptin-induced mRNA expression of ADAMTS-4, ADAMTS-5, MMP-2 and MMP-9 in a dose-dependent manner, which suggested that vaspin may have an anticatabolic effect on rat chondrocytes stimulated with leptin, and prevent the progression of OA by inhibiting the expression of MMPs and ADAMTS.

The production of NO and TNF- $\alpha$ were increased in the chondrocytes treated with leptin, and this was significantly inhibited by vaspin. NO and TNF- $\alpha$ are two important inflammatory factors in the progression of OA. OA cartilage can produce high levels of NO, and the increased levels of nitrites identified in the synovial fluid and serum can upregulate NO synthesis (37). NO has also been demonstrated to enhance MMP activity and be involved in joint pain in OA (38). TNF- $\alpha$ is considered to be a trigger of the inflammatory cascade, which can induce a series of inflammatory responses (39). TNF- $\alpha$ has also been shown to decrease the synthesis of major extracellular matrix composition and suppress anabolic activity during chondrocyte metabolism (40). Therefore, the results suggested that vaspin had anti-inflammatory effects on the rat chondrocytes treated with leptin.

The $N F-\kappa B$ signaling pathway is a key regulator of inflammatory cytokine-induced catabolic metabolism in chondrocytes, the activation of which elevates the expression levels of IL-1, nitric oxide synthase 2, MMPs and COX2 (41), resulting in cartilage degradation in OA. Cytoplasmic $\mathrm{NF}-\kappa \mathrm{B}$ proteins exist in an inactive state binding to $\mathrm{I} \kappa \mathrm{B}$, and the $\mathrm{NF}-\kappa \mathrm{B} / \mathrm{I} \kappa \mathrm{B}$ complex cannot translocate to the nucleus. However, upon stimulation with proinflammatory leptin, IKK is phosphorylated and activated, following which I $\mathrm{B}$ is phosphorylated and subsequently degraded. The released $\mathrm{NF}-\kappa \mathrm{B}$ proteins are phosphorylated and then translocated into the nucleus, where they can bind to the promoter of several target genes (42). The present study demonstrated that vaspin inhibited the degradation of $\mathrm{I} \kappa \mathrm{B}$ and inhibited the $\mathrm{NF}-\kappa \mathrm{B}$ pathway, which was consistent with the results obtained in smooth muscle cells (30) and endothelial cells (31). However, the effects of vaspin on other signaling pathways, including AMP-activated protein kinase and Wnt/ $\beta$-catenin, remain to be elucidated and require further investigations.

In conclusion, the results of the present study suggested that vaspin inhibited the leptin-induced expression of $\mathrm{OB}-\mathrm{Rb}$, ADAMTS-4, ADAMTS-5, MMP-2 and MMP-9, and also inhibited the production of NO and TNF- $\alpha$ induced by leptin. These results suggested that vaspin has anti-inflammatory and anticatabolic effects in chondrocytes. These effects, at least in part, are likely due to inhibition of the NF- $\kappa \mathrm{B}$ pathway.

\section{Acknowledgements}

This study was supported by the National Natural Science Foundation of China (grant no. 81401824).

\section{References}

1. Mobasheri A and Batt M: An update on the pathophysiology of osteoarthritis. Ann Phys Rehabil Med 59: 333-339, 2016.

2. Roos EM and Arden NK: Strategies for the prevention of knee osteoarthritis. Nat Rev Rheumatol 12: 92-101, 2016.

3. Radin EL, Paul IL and Rose RM: Role of mechanical factors in pathogenesis of primary osteoarthritis. Lancet 1: 519-522, 1972.

4. Carman WJ, Sowers M, Hawthorne VM and Weissfeld LA: Obesity as a risk factor for osteoarthritis of the hand and wrist: A prospective study. Am J Epidemiol 139: 119-129, 1994.

5. Poonpet $\mathrm{T}$ and Honsawek S: Adipokines: Biomarkers for osteoarthritis? World J Orthop 5: 319-327, 2014.

6. Wang X, Hunter D, Xu J and Ding C: Metabolic triggered inflammation in osteoarthritis. Osteoarthritis Cartilage 23: 22-30, 2015.

7. Ku JH, Lee CK, Joo BS, An BM, Choi SH, Wang TH and Cho HL: Correlation of synovial fluid leptin concentrations with the severity of osteoarthritis. Clin Rheumatol 28: 1431-1435, 2009. 
8. Lübbeke A, Finckh A, Puskas GJ, Suva D, Lädermann A, Bas S, Fritschy D, Gabay C and Hoffmeyer P: Do synovial leptin levels correlate with pain in end stage arthritis? Int Orthop 37: 2071-2079, 2013

9. Otero M, Gomez Reino JJ and Gualillo O. Synergistic induction of nitric oxide synthase type II: In vitro effect of leptin and interferon-gamma in human chondrocytes and ATDC5 chondrogenic cells. Arthritis Rheum 48: 404-409, 2003.

10. Otero M, Lago R, Lago F, Reino JJ and Gualillo O: Signalling pathway involved in nitric oxide synthase type II activation in chondrocytes: Synergistic effect of leptin with interleukin-1. Arthritis Res Ther 7: R581-R591, 2005.

11. Yaykasli KO, Hatipoglu OF, Yaykasli E, Yildirim K, Kaya E, Ozsahin M, Uslu M and Gunduz E: Leptin induces ADAMTS-4, ADAMTS-5, and ADAMTS-9 genes expression by mitogen-activated protein kinases and NF- $\kappa \mathrm{B}$ signaling pathways in human chondrocytes. Cell Biol Int 39: 104-112, 2015.

12. Lam QL and Lu L: Role of leptin in immunity. Cell Mol Immunol 4: 1-13, 2007.

13. Scotece M and Mobasheri A: Leptin in osteoarthritis: Focus on articular cartilage and chondrocytes. Life Sci 140: 75-78, 2015.

14. Hida K, Wada J, Eguchi J, Zhang H, Baba M, Seida A, Hashimoto I, Okada T, Yasuhara A, Nakatsuka A, et al: Visceral adipose tissue-derived serine protease inhibitor: A unique insulin-sensitizing adipocytokine in obesity. Proc Natl Acad Sci USA 102: 10610-10615, 2005.

15. Seeger J, Ziegelmeier M, Bachmann A, Lössner U, Kratzsch J, Blüher M, Stumvoll M and Fasshauer M: Serum levels of the adipokine vaspin in relation to metabolic andrenal parameters J Clin Endocrinol Metab 93: 247-251, 2008.

16. Tan BK, Heutling D, Chen J, Farhatullah S, Adya R, Keay SD, Kennedy CR, Lehnert H and Randeva HS: Metformin decreases the adipokine vaspin in overweight women with polycystic ovary syndrome concomitant with improvement in insulin sensitivity and a decrease in insulin resistance. Diabetes 57: 1501-1507, 2008.

17. Caminos JE, Bravo SB, Garcés MF, González CR, Cepeda LA, González AC, Nogueiras R, Gallego R, García-Caballero T, Cordido $\mathrm{F}$, et al: Vaspinand amylin are expressed in human and rat placenta and regulated by nutritional status. Histol Histopathol 24: 979-990, 2009.

18. Blüher M: Vaspin in obesity and diabetes: Pathophysiological and clinical significance. Endocrine 41: 176-182, 2012.

19. Senolt L, Polanská M, Filková M, Cerezo LA, Pavelka K, Gay S, Haluzík M and Vencovsky J: Vaspin and omentin: New adipokines differentially regulated at the site of inflammation in rheumatoid arthritis. Ann Rheum Dis 69: 1410-1411, 2010.

20. Maijer KI, Neumann E, Müller-Ladner U, Drop DA, Ramwadhdoebe TH, Choi IY, Gerlag DM, de Hair MJ and Tak PP Serum Vaspin Levels Are Associated with the Development of Clinically Manifest Arthritis in Autoantibody-Positive Individuals. PLoS One 10: e144932, 2015.

21. Bao JP, Jiang LF, Chen WP, Hu PF and Wu LD: Expression of vaspin in the joint and the levels in the serum and synovial fluid of patients with osteoarthritis. Int J Clin Exp Med 7: 3447-3453, 2014.

22. Bao JP, Jiang LF, Li J, Chen WP, Hu PF and Wu LD: Visceral adipose tissue-derived serine protease inhibitor inhibits interleukin-1 $\beta$-induced catabolic and inflammatory responses in murine chondrocytes. Mol Med Rep 10: 2191-2197, 2014.

23. Livak KJ and Schmittgen TD: Analysis of relative gene expression data using real-time quantitative PCR and the 2(-Delta Delta C(T)) method. Methods 25: 402-408, 2001.

24. Dozio E, Corsi MM, Ruscica M, Passafaro L, Steffani L, Banfi G and Magni P: Adipokine actions on cartilage homeostasis. Adv Clin Chem 55: 61-79, 2011.
25. Hutcheson J: Adipokines influence the inflammatory balance in autoimmunity. Cytokine 75: 272-279, 2015.

26. Zhang Y, Proenca R, Maffei M, Barone M, Leopold L and Friedman JM: Positional cloning of the mouse obese gene and its human homologue. Nature 372: 425-432, 1994.

27. Toussirot É, Michel F, Binda D and Dumoulin G: The role of leptin in thepathophysiology of rheumatoid arthritis. Life Sci 140: 29-36, 2015.

28. Bao JP, Chen WP, Feng J, Hu PF, Shi ZL and Wu LD: Leptin plays a catabolic role on articular cartilage. Mol Biol Rep 37: 3265-3272, 2010

29. Wada J: Vaspin: A novel serpin with insulin-sensitizing effects. Expert Opin Investig Drugs 17: 327-333, 2008.

30. Li H, Peng W, Zhuang J, Lu Y, Jian W, Wei Y, Li W and Xu Y: Vaspin attenuates high glucose-induced vascular smooth muscle cells proliferation and chemokinesis by inhibiting the MAPK, PI3K/Akt and NF- $\mathrm{KB}$ signaling pathways. Atherosclerosis 228: 61-68, 2013.

31. Jung CH, Lee MJ, Kang YM, Lee YL, Yoon HK, Kang SW, Lee WJ and Park JY: Vaspin inhibits cytokine-induced nuclear factor-kappa B activation and adhesion molecule expression via AMP-activated protein kinase activation in vascular endothelial cells. Cardiovasc Diabetol 13: 41, 2014

32. Kukla M, Mazur W, Buldak RJ and Zwirska-Korczala K: Potential role of leptin, adiponectin and three novel adipokines-visfatin, chemerin and vaspin-in chronic hepatitis. Mol Med 17: 1397-1410, 2011.

33. Ghilardi $\mathrm{N}$ and Skoda RC: The leptin receptor activates janus kinase 2 and signals for proliferation in a factor-dependent cell line. Mol Endocrinol 11: 393-399, 1997.

34. Sinha MK, Sturis J, Ohannesian J, Magosin S, Stephens T, Heiman ML, Polonsky KS and Caro JF: Ultradian oscillations of leptin secretion in humans. Biochem Biophys Res Commun 228: 733-738, 1996.

35. Song RH, Tortorella MD, Malfait AM, Alston JT, Yang Z, Arner EC and Griggs DW: Aggrecan degradation in human articular cartilage explants is mediated by both ADAMTS- 4 and ADAMTS-5. Arthritis Rheum 56: 575-585, 2007.

36. Lipari L and Gerbino A: Expression of gelatinases (MMP-2, MMP-9) in humanarticular cartilage. Int J Immunopathol Pharmacol 26: 817-823, 2013

37. Pelletier JP, Martel-Pelletier J and Abramson SB: Osteoarthritis, an inflammatory disease: Potential implication for the selection of new therapeutic targets. Arthritis Rheum 44: 1237-1247, 2001.

38. Murrell GA, Jang D and Williams RJ: Nitric oxide activates metalloprotease enzymes in articular cartilage. Biochem Biophys Res Commun 206: 15-21, 1995.

39. Miller RE, Miller RJ and Malfait AM: Osteoarthritis joint pain: The cytokine connection. Cytokine 70: 185-193, 2014.

40. Blasioli DJ and Kaplan DL: The roles of catabolic factors in the development of osteoarthritis. Tissue Eng Part B Rev 20: 355-363, 2014.

41. Goldring MB and Otero M: Inflammation in osteoarthritis. Curr Opin Rheumatol 23: 471-478, 2011.

42. Marcu KB, Otero M, Olivotto E, Borzi RM and Goldring MB NF-kappaB signaling: Multiple angles to target OA. Curr Drug Targets 11: 599-613, 2010. 